\title{
Development of lipid micromatrices based sustained release tablets of glipizide: suitability of stearic acid as release retardant
}

\author{
Deepak Singh $^{1}$, Vijay Sharma ${ }^{2} *$ Kamla Pathak ${ }^{3}$ \\ ${ }^{1}$ Rajiv Academy for Pharmacy, Delhi Mathura Road, P.O. Chhatikara, Mathura-281001, India \\ ${ }^{2}$ Department of Pharmaceutics, Sri Sai College of Pharmacy, Dalhousie Road, Badhani, Pathankot - 145001, Punjab, India \\ ${ }^{3}$ Department of Pharmaceutics, Pharmacy College Saifai, UPRIMS \& R, Saifai, Etawah -206130, Uttar Pradesh, India
}

Received: Mar 26, 2016, Revised: Apr 28, 2016, Accepted: Apr 30, 2016

\begin{abstract}
The objective of research was to explore the suitability of lipids like compritol 888 ATO and stearic acid as release retardant to develop sustained release (SR) tablets. The SR micromatrices of lipid (s) and glipizide were prepared (LM1-LM6) as intermediate product by fusion method and assessed for various pharmacotechnical properties. Micromatrices were formulated as SR tablets (F1-F6) by direct compression method and subjected to Pharmacopoeial and Non Pharmacopoeial tests. In vitro drug release behavior of SR tablets demonstrated incomplete release of drug from compitrol based formulations whereas stearic acid based formulations (F4-F6) released more than $90 \%$ drug in $12 \mathrm{~h}$ with F5 displaying maximum \%CDR of $95.70 \pm 0.78 \%$. A $\mathrm{t}_{50 \%}$ of $3 \mathrm{~h}$ exhibited by F5 was significantly lower $(2.7 \mathrm{~h})$ than of marketed formulation (Glytop SR ${ }^{\circledR}\left(\mathrm{t}_{50 \%}=5.7 \mathrm{~h}\right)$ ). Similarity and dissimilarity factor for F5, with reference to Glytop $\mathrm{SR}^{\circledR}$ was $21.65 \%$ and $26.34 \%$ respectively, suggesting F5 has potential to exercise better control on drug release. Scanning Electron Microscopy (SEM) revealed drug particles embedded in stearic acid micromatrices that were confirmed by The X-ray powder diffraction (XRPD) and simultaneously Diffuse Reflectance Infrared Fourier Transform (DRIFT) confirmed the stability of F5. Conclusively, stearic acid explored as a suitable lipidic release retardant for development of SR tablet of glipizide that were stable for the test period of 6 months.
\end{abstract}

Keywords: Glipizide, stearic acid, drug lipid micromatrices, sustained release tablet

$$
\text { Pharm Biomed Res 2016: 2(2): 9-30 DOI: 10.18869/acadnuh.nhr.2.2.9 }
$$

\section{Introduction}

Lipid and waxy materials are frequently used as bulk excipients in the development of sustained and controlled release tablet dosage forms. Lipids and waxes possess several advantages over other materials like chemical inertness, ease of manufacturing with high reproducibility without the application of expensive instrumentation, as well as low cost of production (1). Lipid excipients in pharmaceutical preparations are widely applicable to improve the processing or stability of the formulation, enhancement or reduction in cellular or systemic absorption of active entity from the formulation, more effective drug targeting and sustained or controlled delivery of the drug (2). The lipid excipients like carnauba wax (3), bees wax (4), glycerides (5), stearyl 
alcohol (6) and cotton seed oil (7) have been employed for the formulation of sustained release tablet dosage form (8). On the other hand, waxy excipients form water insoluble matrices that result in the formation of inert matrices which are mostly compatible with the active entity. A variety of matrix formulations, comprising granules and tablets, have been developed in order to achieve effective sustained drug release (9). Compitrol 888 ATO is a lipid excipient that has been utilized as lubricant in tablet manufacturing but recently has found application as sustained release agent (10). It has been investigated as hot melt coating agent for retarding the release of theophylline over an extended period of time (11) and to delay drug release from SR ketoprofen micropellet formulations prepared from beeswax-cotton seed oil mixture (4). In another study, SR lipophilic matrix tablet of highly water soluble potassium citrate with a high loading dose was developed using stearyl alcohol and stearic acid in carnauba wax (12). Keeping in view the sustaining potential of lipids and the inert matrix forming capability of waxes, compritol 888 ATO and stearic acid were used as the release retardant materials for development of micromatrices of glipizide.

Glipizide is an effective oral blood glucose lowering drug used in type II diabetes mellitus (13). The usual dose by mouth is 5 mg twice or thrice daily before meal, whereas $10 \mathrm{mg}$ commercial sustained release preparation may be administered once daily. Though SR tablet is commercially available, present investigation aims to develop an alternative lipid excipient based sustained release formulation of glipizide and assess its performance in comparison to the commercially available equivalent dosage form of the drug.

\section{Materials and methods}

\section{Materials}

Glipizide (mol. Wt. 445.5; M.P 208-209 ${ }^{\circ} \mathrm{C}$ ) was a gift sample from Wings Pharmaceuticals, Delhi, India. Compritol 888 ATO was kindly supplied by Gattefosse S.A., Saint Priest, France as a gift sample. Stearic acid was procured from Arora Pharmaceuticals Pvt. Ltd., New Delhi, India. Aerosil and talc were purchased from $\mathrm{S}$. Merck (India) Limited, India. Microcrystalline cellulose and magnesium stearate were obtained from S.D. fine Chemicals Limited, Mumbai, India. All other chemicals used were of analytical grade and commercially purchased.

\section{Methods}

\section{Drug-excipient compatibility}

Glipizide, pure lipid excipients (compritol 888 ATO and stearic acid) and binary mixtures (1:1 and 1:3) of drug with excipients separately were subjected to physical and chemical compatibility studies, in order to determine the interaction between drug and excipients used. Pure drug, lipid excipient (s) and binary mixture thereof were separately kept in sealed vials that were stored at two different temperatures $\left(4{ }^{\circ} \mathrm{C}\right.$ and $\left.25{ }^{\circ} \mathrm{C}\right)$ with and without moisture $(5 \% \mathrm{w} / \mathrm{w})$ for 15 days (14). The stored samples were then examined for discoloration, liquefaction, caking and odour or gas formation 
periodically. Differential scanning calorimetry analysis was performed at the end of test period to assess chemical compatibility between drug and various lipid excipients. Samples were analyzed using differential scanning calorimeter (SIIO 6300 with auto-sampler, SIIO, Japan) at a scan rate of $5{ }^{\circ} \mathrm{C} / \mathrm{min}$ under a flow rate of dry $\mathrm{N}_{2}$ gas $(50 \mathrm{ml} / \mathrm{min})$ from $25{ }^{\circ} \mathrm{C}$ to $250{ }^{\circ} \mathrm{C}$ and thermograms were recorded.

Composition design and preparation of drug-lipid micromatrices

A total of six batches (Table 1) of drug lipid micromatrices (LM1-LM6) were prepared by hot fusion method (7). Briefly, the lipid excipient was melted with continuous stirring in porcelain dish placed on a water bath maintained at $80 \pm 2{ }^{\circ} \mathrm{C}$. Glipizide $(20 \mathrm{mg})$ was added to the molten lipids with continuous stirring. The dispersion was allowed to cool down and solidify. The solid mass was scraped using stainless steel spatula and screened through the sieve number 16 (aperture size $1 \mathrm{~mm}$ ). The obtained product was termed as drug lipid micromatrices (LM1-LM6) and was stored in desiccators till further evaluation.

\section{Evaluation of drug-lipid micromatrices \\ Drug content}

Drug content was determined by weighing $50 \mathrm{mg}$ of drug- lipid micromatrices followed by extraction with suitable media. The extract was then analyzed spectrophotometrically at $275.8 \mathrm{~nm}$ (UV spectrophotometer, Shimadzu Pharmaspec1700, Tokyo, Japan) and suitably diluted if required.

\section{Micromeritic characterization}

The mean diameter of prepared micromatrices was determined by sieving method (15). A series of standard sieves calibrated by the National Bureau of Standards (British standards of sieves) (16). The fraction retained on each sieve was weighed and used for calculation of various micromeritic parameters. The data was analyzed for normal, log normal, cumulative percent frequency distribution and probability curves. The relevant diameters such as geometric mean weight, diameter and standard deviation were estimated and documented.

\section{Rheological characterization}

Static funnel method was used to determine the angle of repose of prepared drug-lipid micromatrices (17). The bulk density and

Table 1 Formulation composition for drug-lipid micromatrices (LM 1 - LM6)

\begin{tabular}{lcccccc}
\hline Ingredients & \multicolumn{7}{c}{ Formulation code } \\
\cline { 2 - 7 } & LM1 & LM2 & LM3 & LM4 & LM5 & LM6 \\
\hline Glipizide (mg) & 20 & 20 & 20 & 20 & 20 & 20 \\
Compritol 888 ATO (\%w/w) & 10 & 20 & 30 & -- & -- & -- \\
Stearic acid (\%w/w) & -- & -- & -- & 15 & 20 & 25 \\
\hline
\end{tabular}


tapped density was determined and the values obtained for bulk density and tapped density were used to calculate Carr's compressibility index (CI) and Hausner's ratio (HR) by using following equations:

$$
\begin{gathered}
\mathrm{CI}=\text { Tapped Density }- \text { Bulk Density } / \\
\text { Tapped Density } \times 100
\end{gathered}
$$

HR = Tapped Density / Bulk Density

\section{Formulation of SR tablets}

For the development of sustained release (SR) tablets of glipizide, the drug-lipid micromatrices (LM1-LM6) were taken equivalent to $10 \mathrm{mg}$ of glipizide. Aerosil was used as antiadherent and microcrystalline cellulose was used as filler in all the formulations. Magnesium stearate $(0.8 \mathrm{mg})$ was added in all the formulations as lubricant and mixed with the micromatrices before compression (Table 2). Tablets were prepared by direct compression on electrically operated single punch tablet machine $\left(\mathrm{HICON}^{\circledR}\right.$, Grover Enterprises, New Delhi, India). The tablet formulations were coded as F1-F6 and stored in desiccators until evaluation.

\section{Evaluation of prepared glipizide SR tablets \\ Non-pharmacopoeial evaluation}

Six tablets from each batch were selected at random and thickness of prepared glipizide SR tablets was determined by using callipergauge (SER 41200807, Mitutoyo Corporation, Tokyo, Japan). The hardness of tablets $(n=6)$ was tested by Monsanto hardness tester $\left(\mathrm{HICON}^{\circledR}\right.$, Grover Enterprises, New Delhi, India). Friability of the tablets was determined by using Roche friabilator $\left(\mathrm{HICON}^{\circledR}\right.$, Grover Enterprises, New Delhi, India). The friabilator was operated for 100 revolutions; the tablets were collected, de-dusted and reweighed (16). Friability was calculated using following equation:

$\%$ Friability $=$ Initial weight - Final weight $/$ Initial weight $\times 100$

\section{Pharmacopoeial evaluation}

Weight variation and content uniformity

Tablet weight variation was determined as described in Indian Pharmacopoeia (18). To assess the uniformity of drug content two tablets from each batch were selected at random and crushed into powder in a glass mortar-pestle. Accurately weighed $10 \mathrm{mg}$ of tablet powder was dissolved in $100 \mathrm{~mL}$ phosphate buffer $\mathrm{pH} 7.4$, filtered through $0.45 \mu$ filter, the resultant solution was diluted suitably with phosphate buffer $\mathrm{pH}$ 7.4 analyzed spectrophotometrically. The experiment was carried out in triplicate and average values were recorded.

\section{In-vitro drug release}

The drug release from prepared tablets was studied by using USP-I (Basket) apparatus, containing $900 \mathrm{~mL}$ dissolution medium maintained at $37 \pm$ $2{ }^{\circ} \mathrm{C}$ at $100 \mathrm{rpm}$. For first $2 \mathrm{~h}$ the study was carried out in $0.1 \mathrm{~N} \mathrm{HCl}$ buffer, $\mathrm{pH} 1.2$ followed by phosphate buffer, pH 7.4 in next 10 h. After every one hour interval, $5 \mathrm{~mL}$ aliquots were withdrawn and replenished with fresh dissolution medium. 
Table 2 Formulation design for development of micromatrices based glipizide SR tablets (F1- F6)

\begin{tabular}{|c|c|c|c|c|c|c|}
\hline \multirow{2}{*}{$\begin{array}{c}\text { Ingredients } \\
\text { (mg) }\end{array}$} & \multicolumn{6}{|c|}{ Formulation code } \\
\hline & F1 & F2 & F3 & F4 & F5 & F6 \\
\hline $\begin{array}{l}\text { Drug-lipid } \\
\text { micromatrices }\end{array}$ & $\begin{array}{c}\text { LM1 } \\
\text { Eq. to } 10 \\
\text { mg of } \\
\text { glipizide }\end{array}$ & $\begin{array}{l}\text { LM2 } \\
\text { Eq. to } 10 \\
\text { mg of } \\
\text { glipizide }\end{array}$ & $\begin{array}{c}\text { LM3 } \\
\text { Eq. to } 10 \\
\text { mg of } \\
\text { glipizide }\end{array}$ & $\begin{array}{l}\text { LM4 } \\
\text { Eq. to } 10 \\
\text { mg of } \\
\text { glipizide }\end{array}$ & $\begin{array}{l}\text { LM5 } \\
\text { Eq. to } 10 \\
\text { mg of } \\
\text { glipizide }\end{array}$ & $\begin{array}{l}\text { LM6 } \\
\text { Eq. to } 10 \\
\text { mg of } \\
\text { glipizide }\end{array}$ \\
\hline Aerosil & 0.5 & 0.5 & 0.5 & 0.5 & 0.5 & 0.5 \\
\hline $\begin{array}{l}\text { Magnesium } \\
\text { stearate }\end{array}$ & 0.8 & 0.8 & 0.8 & 0.8 & 0.8 & 0.8 \\
\hline $\begin{array}{l}\text { Microcrystallie } \\
\text { cellulose }\end{array}$ & $\begin{array}{l}\text { q.s to } \\
100 \mathrm{mg}\end{array}$ & $\begin{array}{l}\text { q.s to } \\
100 \mathrm{mg}\end{array}$ & $\begin{array}{l}\text { q.s to } \\
100 \mathrm{mg}\end{array}$ & $\begin{array}{l}\text { q.s to } \\
100 \mathrm{mg}\end{array}$ & $\begin{array}{l}\text { q.s to } \\
100 \mathrm{mg}\end{array}$ & $\begin{array}{l}\text { q.s to } \\
100 \mathrm{mg}\end{array}$ \\
\hline
\end{tabular}

Amount of drug in each aliquot was assayed spectrophotometrically at $275.8 \mathrm{~nm}$ against a suitable blank. The release study of marketed reference formulation (Glytop $\left.\mathrm{SR}^{\circledR}\right)$ was conducted in similar experimental conditions. The results are expressed as the percentage of the released drug as a function of time according to the released drug content obtained from dissolution studies. All the samples were run in triplicate. Additionally, to calculate swelling ratio, the thickness and diameter of the tablets, before and after the dissolution were measured using caliper gauge and swelling ratio was calculated by the following equation:

$$
\text { Swelling Ratio }=\mathrm{V}_{\mathrm{a}}-\mathrm{V}_{\mathrm{i}} / \mathrm{V}_{\mathrm{i}} \mathrm{X} 100
$$

Where, $\boldsymbol{V}_{\boldsymbol{i}}$ and $\boldsymbol{V}_{\boldsymbol{a}}$ are volume(s) of tablet before and after dissolution, respectively.

Release kinetics and selection of best formulation

The in vitro release data was fitted to various kinetic equations by PCP disso software $2.0 \mathrm{~V}$, Pune India, to elucidate the mechanism of drug release. The kinetic models used were zero order, first order, Higuchi, Korsmeyer-Peppas and HixsonCrowell. The best formulation was selected on the basis of physicochemical characteristics, \%CDR and drug release kinetics, and compared with marketed formulation. The similarity and dissimilarity factors were calculated using below mentioned equations (Eq 5 and 6) 
with respect to marketed formulation $\left(\right.$ Glytop SR ${ }^{\circledR}$ ).

$f_{1}=\left\{\left[\sum_{\mathrm{t}=1}^{\mathrm{n}}\left|\mathrm{R}_{t}-T_{t}\right|\right] /\left[\sum_{t=1}^{n} R_{t}\right]\right\} \bullet 100$

$f_{2}=50 \bullet \log \left\{\left[1+(1 / \mathrm{n}) \sum_{t=1}^{n}\left(R_{t}-T_{t}\right)^{2}\right]^{-0.5} \bullet 100\right\}$

Where, $f_{1}$ is dissimilarity factor and $f_{2}$ is similarity factor; $n$ is the total number of time points considered, ' $R t$ ' is amount dissolved up to time ' $t$ ' from the reference tablet and ' $T t$ ' is the amount dissolved up to time ' $t$ ' from the test tablet.

\section{Scanning Electron Microscopy (SEM)}

The SEM photomicrographs of glipizide, stearic acid, physical mixture of drug with lipid and drug-lipid micromatrices were captured by using FEI Quanta ${ }^{\mathrm{TM}} 200$ scanning electron microscope, USA. Samples were previously coated with silver under argon atmosphere and were examined at different magnifications. The photomicrographs were assessed for shape and surface morphology.

\section{$X$-Ray powder diffraction}

The X-ray powder diffraction patterns of glipizide, stearic acid and drug-lipid micromatrices were obtained using X-ray diffractometer (PW 3040/60 X'pert PRO, Netherland) under Ni-filtered $\mathrm{Cu} \mathrm{K}(\alpha)$ radiation $(\lambda=1.5405980 \AA$ ) at scan step size of $0.020^{\circ}$ applying voltage of $40 \mathrm{kv}$ and a current of $30 \mathrm{~mA}$, for the generator. The samples were exposed to Ni-filtered $\mathrm{Cu} \mathrm{K}$ $(\alpha)$ radiation over a range of $2 \theta$ angles from $10{ }^{\circ} \mathrm{C}$ to $80^{\circ} \mathrm{C}$ and crystallinity index was determined as:

$\%$ Crystallinity Index $=\left(\mathrm{I}_{020}-\mathrm{I}_{\mathrm{am}} / \mathrm{I}_{020}\right) \times 100$

(7)
Where, $\mathrm{I}_{020}$ is intensity at $22.5^{\circ} \mathrm{C}$ and $\mathrm{I}_{\mathrm{am}}$ is lowest $2 \theta$ value near $18^{\circ}$.

\section{Diffuse Reflectance Infrared Fourier} Transform (DRIFT) Spectroscopy

DRIFT spectrophotometric study of glipizide, stearic acid and drug-lipid micromatrices was carried out using diffuse reflectance infrared spectrophotometer (FTIR-8400SCE, Shimadzu Corporation, Tokyo, Japan) to assess the effect of any possible chemical changes. Samples for anlaysis were prepared by mixing with potassium bromide (IR grade) in the ratio of 1:10 and exposed to infrared radiation in the range of 500 to $4000 \mathrm{~cm}^{-1}$.

\section{Stability studies}

The stability testing of was conducted as per ICH Q1A (R2) guidelines and the optimized tablet formulation F5 was stored in stability chamber maintained at $40 \pm 2{ }^{\circ} \mathrm{C}$ and $75 \pm$ $5 \% \mathrm{RH}$ for three months. Sampling was done at the intervals of $0,1,2,3$ and 6 month. The samples were analyzed for their hardness, friability, drug content, in vitro drug release and validated by DRIFT analysis.

\section{Resalts}

\section{Drug - excipient compatibility}

As a result of compatibility studies drug and excipients selected for the development of glipizide SR tablets were found physically compatible and no physical interaction (caking, colour change, liquefaction and odor or gas formation) was observed. Chemical compatibility was analyzed by DSC of pure drug, pure lipid excipient (s) and physical mixture(s) of drug with lipids. The DSC thermogram of glipizide (Fig. 1A) 
Figure 1 DSC thermograms of pure glipizide, lipid excipients and their corresponding binary mixtures (A) GPZ + COMP; (B) GPZ + SA

exhibited a sharp endothermic peak at 209 ${ }^{\circ} \mathrm{C}$ (intensity $=3.2 \mathrm{~mW} / \mathrm{mg}$ and enthalpy ,$\Delta \mathrm{H}$, of $98.72 \mathrm{~J} / \mathrm{g}$ ), that corresponds to the melting point of the drug sample (glipizide). The thermogram of compritol 888 ATO exhibited a sharp melting endotherm at 69.6 ${ }^{\circ} \mathrm{C}$ (intensity $=1.15 \mathrm{~mW} / \mathrm{mg}$ with the $\Delta \mathrm{H}$ value of $71.24 \mathrm{~J} / \mathrm{g}$ ) and was close to its reported melting point of $70{ }^{\circ} \mathrm{C}$ (19). To investigate the interaction between glipizide and compritol 888 ATO, a DSC thermogram of the physical mixture containing pure glipizide and compritol 888 ATO was also recorded that exhibited two different sharp endotherms for each individual component. However, the endothermic peak of glipizide was slightly shifted from $209{ }^{\circ} \mathrm{C}$ to $207.2{ }^{\circ} \mathrm{C}$ with the reduced intensity $(1.65 \mathrm{~mW} / \mathrm{mg})$ and $\Delta \mathrm{H}$ value $(76.92 \mathrm{~J} / \mathrm{g})$. On the other hand compritol 888 ATO exhibited a broad endotherm at $59.4{ }^{\circ} \mathrm{C}$ showing a small intense peak $(0.74 \mathrm{~mW} / \mathrm{mg})$ with slight reduction in the $\Delta \mathrm{H}$ value $(56.48 \mathrm{~J} / \mathrm{g}$ ) (Fig. 1A). The DSC endotherm of stearic acid (Fig. 1B) showed a sharp peak at $60.2{ }^{\circ} \mathrm{C}$ (intensity $=4.6 \mathrm{~mW} / \mathrm{mg} ; \Delta \mathrm{H}=166.4 \mathrm{~J} / \mathrm{g}$ ), corresponding to its melting point (19). The physical mixture exhibited two individual sharp endotherms at $200.9^{\circ} \mathrm{C}$ (intensity = $0.6 \mathrm{~mW} / \mathrm{mg} ; \Delta \mathrm{H}=25.86 \mathrm{~J} / \mathrm{g}$ ) for glipizide and at $59.7^{\circ} \mathrm{C}$ (intensity $=1.8 \mathrm{~mW} / \mathrm{mg} ; \Delta \mathrm{H}$ $=2.32 \mathrm{~J} / \mathrm{g}$ ) for stearic acid, respectively with a definite change in the base line beyond 205 ${ }^{\circ} \mathrm{C}$.

Preparation and characterization of drug lipid micromatrices

A total of six batches (LM1-LM6) of micromatrices were prepared and the percent 
drug content of the micromatrices ranged between of $98.26 \pm 0.26 \%$ to $99.32 \pm 1.33 \%$. Visually, the micromatrices were white to off white on color and appeared as free flowing powder.

\section{Micromeritic characterization}

The drug-lipid micromatrices that were intended to be developed as SR tablets were therefore characterized for various micromeritic parameters- mean particle size, skewness and interquartile coefficient of skewness. The micromeritic study revealed that the average mean particle diameter $\left(\mathrm{d}_{\text {mean }}\right)$ of compitrol micromatrices (LM1LM3) were significantly lower $(\mathrm{P}<0.005)$ stearic acid micromatrices (LM4-LM6; Table 3). The stearic acid based micromatrices had lower enthalpy transition value of $2.32 \mathrm{~J} / \mathrm{g}$, than compritol 888ATO based micromatrices (56.48 J/g) as suggested by DSC thermograms. Particle size distribution data when summarized statistically, exhibited IQCS values, in the range of -0.3210 to -0.5240 for LM1-LM3 and from -0.4960 to -0.5540 for LM4- LM6.

\section{Flow and density characteristics}

The angle of repose for LM1- LM3 ranged between $15 \pm 0.16$ to $17 \pm 0.07^{\circ}$ indicating excellent flowability, while LM4- LM6 showed good flowability as the values lied in the range of $22 \pm 0.14^{\circ}$ to $23 \pm 0.07^{\circ}$ (Table $3)$. Both bulk density and tapped density narrowly ranged between $0.324 \pm 0.09$ to $0.382 \pm 0.09 \mathrm{~g} / \mathrm{ml}$ and $0.402 \pm 0.06$ to 0.462 $\pm 0.07 \mathrm{~g} / \mathrm{ml}$ for all the micromatrices formulations. The numerical values of all the drug-lipid micromatrices were found closer to 1.25 (Table 3). The values obtained for

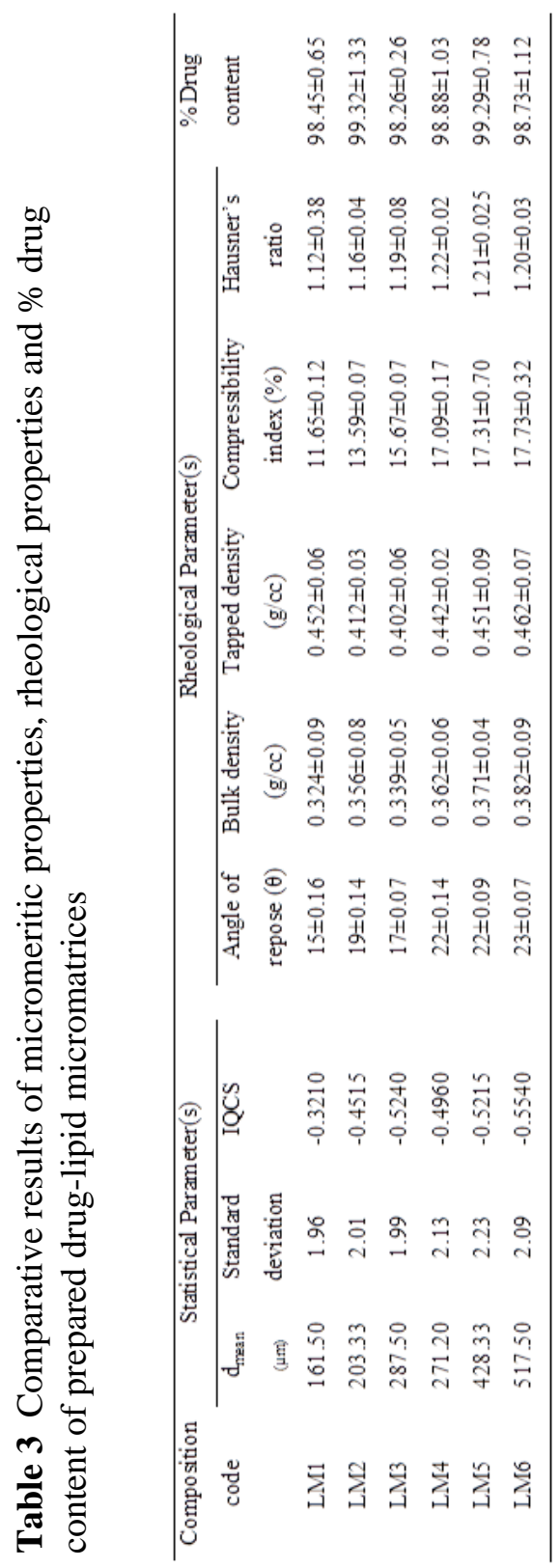

Carr's index suggest that all the micromatrices have shown excellent to good flow characteristics with high degree of compressibility (Table 3 ).

Development and charactrization of $S R$ tablets

The sustained release tablets of glipizide prepared by direct compression were 
evaluated for physical, chemical and performance characteristics. The hardness of prepared tablets was found to be in the range of $4.08 \pm 0.34$ to $5.58 \pm 0.34 \mathrm{~kg} / \mathrm{cm}$ (Table 4). All the prepared tablet formulations exhibited friability value less than $1 \%$ which meets the pharmacopoeial standard limit (20). None of the individual tablet weight found deviate more than $8.5 \%$ from the average weight as per limit and none deviated more than twice of that percentage. Results showed that all the tablet batches passed the weight variation test (18). The drug content was within the range of $92.43 \pm$ 0.66 to $98.69 \pm 0.45 \%$ (Table 4 ).

\section{In vitro drug release}

A comparative in vitro drug release profiles of sustained release tablet formulations of glipizide (F1- F6) are shown in Figure 2A and the exhibited in vitro drug release pattern of marketed formulation (Glytop $\mathrm{SR}^{\circledR}$ ) is shown in Figure 2B, which clearly indicate that \%CDR achieved by Glytop $\mathrm{SR}^{\circledR}$ was $94.12 \pm 1.02 \%$ in $12 \mathrm{~h}$. In compitrol based formulations, highest \%CDR drug release was obtained by the formulation F1 (81.72 \pm $0.70 \%$ ) while the least was observed with formulation F3 $(59.73 \pm 0.79 \%)$. On the other hand in stearic acid containing formulations, F4 showed the highest \%CDR $(99.64 \pm 0.78 \%)$ and $\mathrm{F} 6$ exhibited least value of $89.39 \pm 0.99 \%$.

Thus, F4 showed maximum \%CDR while F6 that contained highest concentration of stearic acid exhibited least \%CDR at $12 \mathrm{~h}$ and was abandoned. Amongst F4 and F5, formulation $\mathrm{F} 4$ released the entire drug (99.64 $\pm 0.78 \%)$ within $11 \mathrm{~h}$ while F5 exhibited the \%CDR of $95.70 \pm 0.78 \%$. To elucidate the possible mechanisms of drug release through $\mathrm{F} 5$, the micromatrices (LM5) that were used in the formulation of F5 was extensively studied by SEM, XRPD and DRIFT.

\section{Scanning electron microscopy}

The scanning electron photomicrographs of glipizide, stearic acid and its physical mixture and micromatrices are shown in

Table 4 Comparative data for various pharmacopoeial and non pharmacopoeial evaluation parameters of prepared sustained release tablets (F1-F6)

\begin{tabular}{ccccccc}
\hline $\begin{array}{c}\text { Formulatio } \\
\mathrm{n}\end{array}$ & $\begin{array}{c}\text { Thickness } \\
(\mathrm{mm}) \pm\end{array}$ & $\begin{array}{c}\text { Friability } \\
(\%) \pm\end{array}$ & $\begin{array}{c}\text { Hardness } \\
(\mathrm{mm}) \pm\end{array}$ & $\begin{array}{c}\text { \% Drug } \\
\text { Content } \pm\end{array}$ & $\begin{array}{c}\text { Average weight } \\
(\mathrm{mg}) \pm\end{array}$ & $\begin{array}{c}\text { Weight } \\
\text { variation }\end{array}$ \\
code & S.D & S.D & S.D & S.D & S.D & test \\
\hline F1 & $3.91 \pm 0.32$ & $0.53 \pm 0.84$ & $5.58 \pm 0.34$ & $95.41 \pm 0.44$ & $98.28 \pm 0.38$ & Pass \\
F2 & $3.13 \pm 0.03$ & $0.61 \pm 0.45$ & $5.08 \pm 0.34$ & $92.43 \pm 0.66$ & $99.37 \pm 0.69$ & Pass \\
F3 & $3.75 \pm 0.40$ & $0.58 \pm 0.63$ & $4.08 \pm 0.34$ & $96.57 \pm 0.05$ & $98.96 \pm 0.82$ & Pass \\
F4 & $3.10 \pm 0.01$ & $0.63 \pm 0.66$ & $5.75 \pm 0.25$ & $97.36 \pm 0.32$ & $97.89 \pm 0.47$ & Pass \\
F5 & $3.09 \pm 0.09$ & $0.59 \pm 0.92$ & $5.08 \pm 0.04$ & $98.69 \pm 0.45$ & $98.78 \pm 0.27$ & Pass \\
F6 & $3.08 \pm 0.01$ & $0.56 \pm 0.43$ & $5.01 \pm 0.28$ & $96.90 \pm 0.89$ & $99.12 \pm 0.08$ & Pass \\
\hline
\end{tabular}



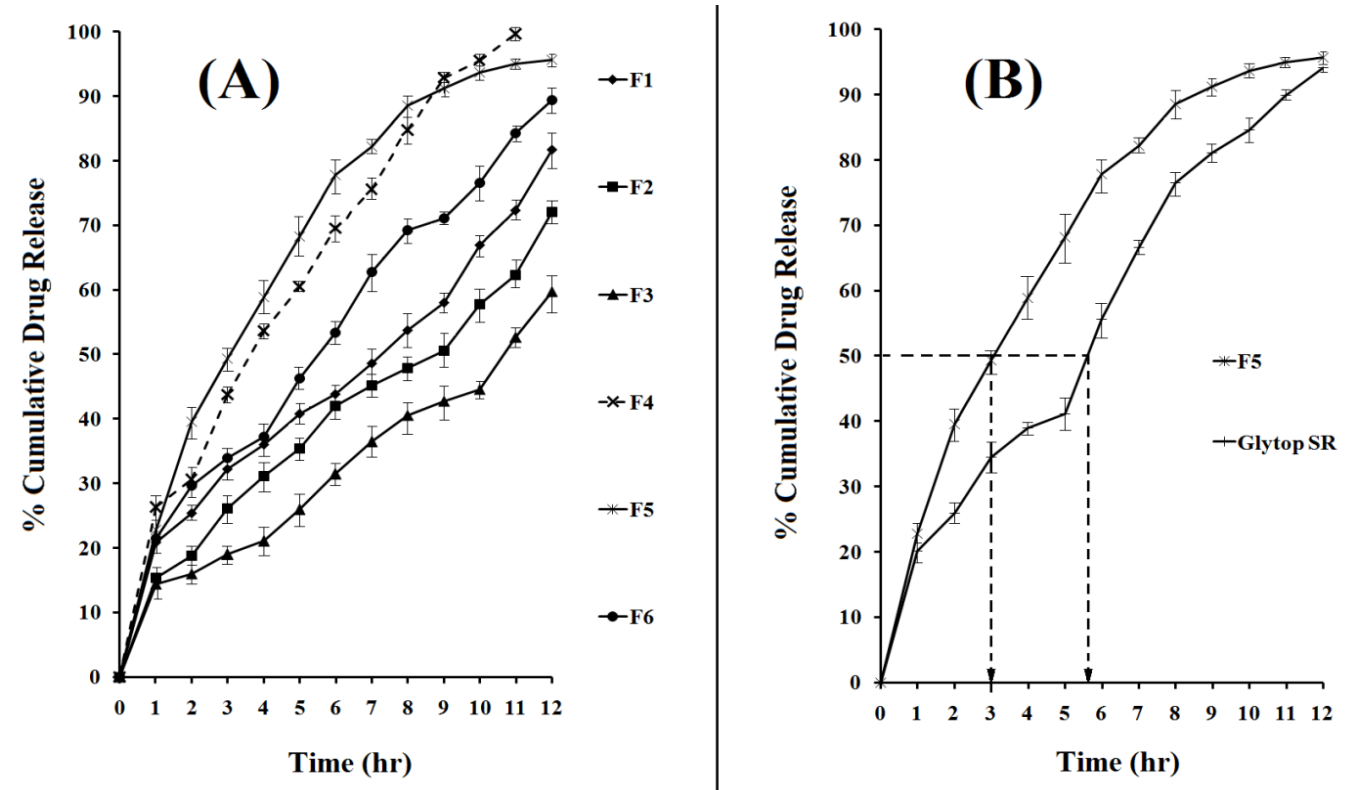

Figure 2 Comparative \%cumulative drug release profile of (A) Sustained release tablets of glipizide (F1 - F6); (B) F5 vs. Glytop SR ${ }^{\circledR}$

Figure 3. The drug powder consisted of irregular, elongated slab shaped crystals (3a). The microphotograph of stearic acid appears as irregular shaped flattened amorphous flakes with smooth surface (3b). In the physical mixture, the glipizide crystals were clearly detectable as the glipizide crystals adhered on the surface of stearic acid (3c) whereas the micrograph of micromatrix (LM5; Fig. 3d) showed some longitudinal drug particles found adhered on the surface of micromatrices along with the uniform distribution of drug particles on/within the lipid micromatrices (Fig 3d).

\section{$X$ - Ray powder diffraction}

The X-ray powder diffractogram of glipizide showed different scattering angles from $11.7^{\circ}$ to $26.2^{\circ}$ with high signal intensities.

The X-ray diffraction pattern of stearic acid exhibited very strong and distinct peaks at $2 \theta$ values of $11.3^{\circ}, 15.9^{\circ}$ and $22^{\circ}$ (Fig. 4). Micromatrices $(\mathrm{GPZ}+\mathrm{SA})$ showed the intense unchanged peaks of stearic acid, while there is no evidence of intense signals exhibited by glipizide. The \%crystallinity index of glipizide and stearic acid was calculated as $72.91 \%$ and $38.72 \%$ respectively, while the crystallinity index of glipizide within the prepared micromatrices got reduced to $44.18(\mathrm{GPZ}+\mathrm{SA}$; Fig. 4), respectively.

\section{DRIFT analysis}

The spectra for glipizide (Fig. 5) showed the appearance of characteristic peaks at $3334.69 \mathrm{~cm}^{-1}$ and $1528 \mathrm{~cm}^{-1}$ for $\mathrm{N}-\mathrm{H}$ stretching and bending vibrations respectively. The stretching vibrations were observed at $1687.60 \mathrm{~cm}^{-1}$ and $1654.81 \mathrm{~cm}^{-1}$ for $\mathrm{C}=\mathrm{O}$ of $-\mathrm{NHCONH}-$ and $-\mathrm{CONH}$ group, respectively. In the spectra stretching vibrations appeared at $1166.85 \mathrm{~cm}^{-1}$ for $\mathrm{SO}_{2}$ group. Another stretching vibration can be observed at $1027 \mathrm{~cm}^{-1}$ for $\mathrm{C}-\mathrm{O}$ group and a bending vibration for $\mathrm{C}-\mathrm{H}$ appeared at $892.98 \mathrm{~cm}^{-1}$ for disubstituted benzene (21). The DRIFT spectra of stearic acid (Fig. 5) 

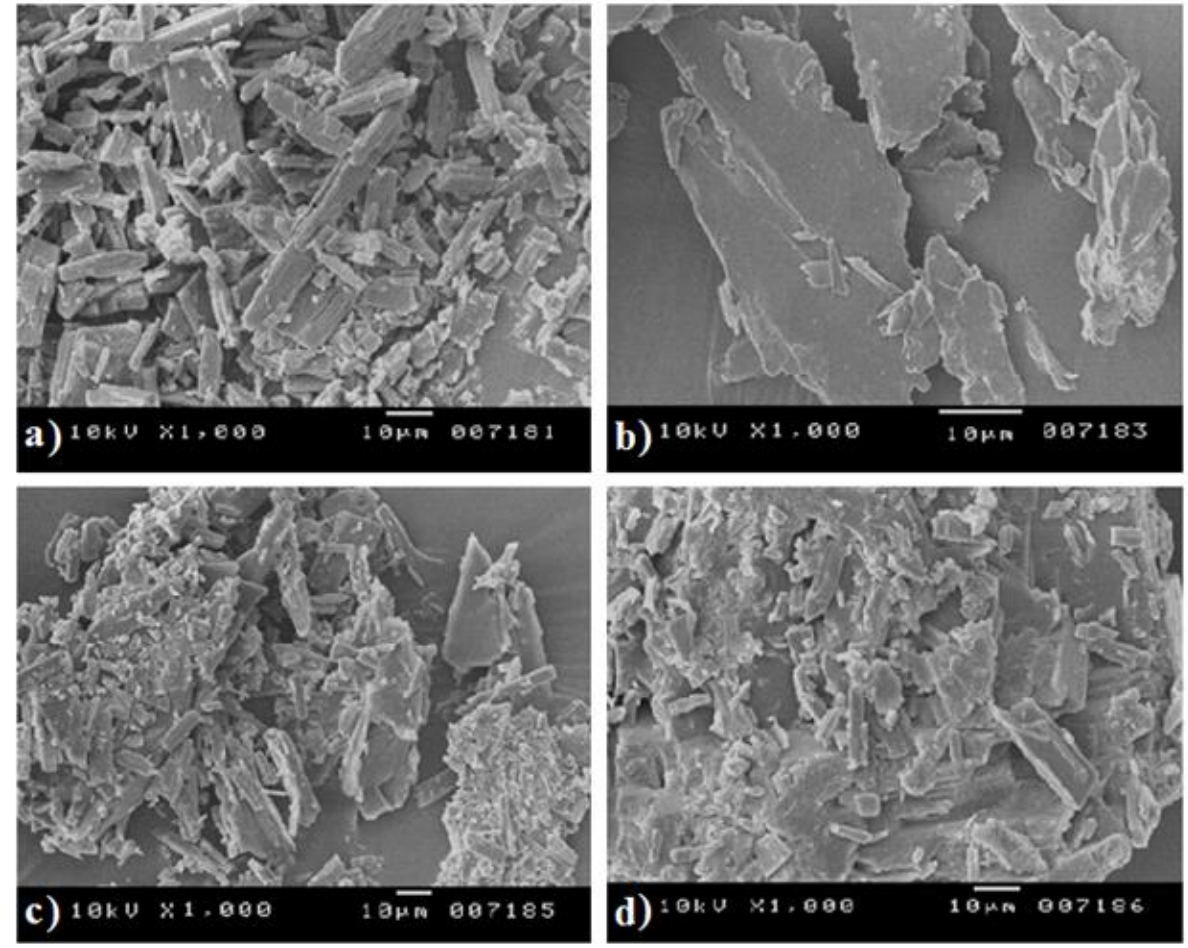

Figure 3 Scanning Electron Photomicrographs of a) Glipizide; b) Stearic Acid; c) Binary mixture of glipizide \& stearic acid and d) Drug- Lipid Micromatrices (LM5)

showed the appearance of strong peaks at $3346.27 \mathrm{~cm}^{-1}$ and $1693.38 \mathrm{~cm}^{-1}$ for $\mathrm{O}-\mathrm{H}$ and $\mathrm{C}=\mathrm{O}$ stretching vibrations of $-\mathrm{COOH}$. The stretching peaks at $2916.17 \mathrm{~cm}^{-1}$ and $2852.52 \mathrm{~cm}^{-1}$ for $\mathrm{C}-\mathrm{H}$ stretching of $-\mathrm{CH}_{3}$ for $-\mathrm{CH}_{2}$ group (22). The DRIFT spectra of drug lipid micromatrices showed the appearance of strong peaks of both the components at $3321.19 \mathrm{~cm}^{-1}$ and 1529.45 $\mathrm{cm}^{-1}$ for $\mathrm{N}-\mathrm{H}$ stretching and bending vibrations. Peaks can also be observed at $1693.38 \mathrm{~cm}^{-1}$ and $1656.42 \mathrm{~cm}^{-1}$ for $\mathrm{C}=\mathrm{O}$ of $\mathrm{NHCONH}-$ and $-\mathrm{CONH}$ group, respectively (23). A stretching peak was observed at $1166.85 \mathrm{~cm}^{-1}$ for $\mathrm{SO}_{2}$. Peak appeared at $1027.99 \mathrm{~cm}^{-1}$ for $\mathrm{C}-\mathrm{O}$ stretching vibrations and a bending vibration was observed at $894.91 \mathrm{~cm}^{-1}$ for $\mathrm{C}-\mathrm{H}$ of disubstituted benzene, $3346.27 \mathrm{~cm}^{-1}$ for $\mathrm{O}-\mathrm{H}$ stretching vibrations, $2920.03 \mathrm{~cm}^{-1}$ and $2854.45 \mathrm{~cm}^{-1}$ for $\mathrm{C}-\mathrm{H}$ stretching of $-\mathrm{CH}_{3}$ and $-\mathrm{CH}_{2}$ group (Fig. 5).

\section{Release kinetics}

The release profiles of formulation F5 and marketed formulation (Glytop SR ${ }^{\circledR}$ ) were subjected to mathematical modeling where F5 showed mixed order kinetics or Higuchi model $\left(r^{2}=0.9876\right)$ which confirmed that the F5 formulation was a sustained release formulation. As stearic acid showed the highest value for dissolution rate constant $(\mathrm{k}$ = 3.239) with F5 among all the three formulations. Diffusion exponent exhibited by F5 (0.6776) clearly indicate that the drug release from tablet matrices was erosion with diffusion, as all formulations exhibited non Fickian drug release. The erosion (negative 

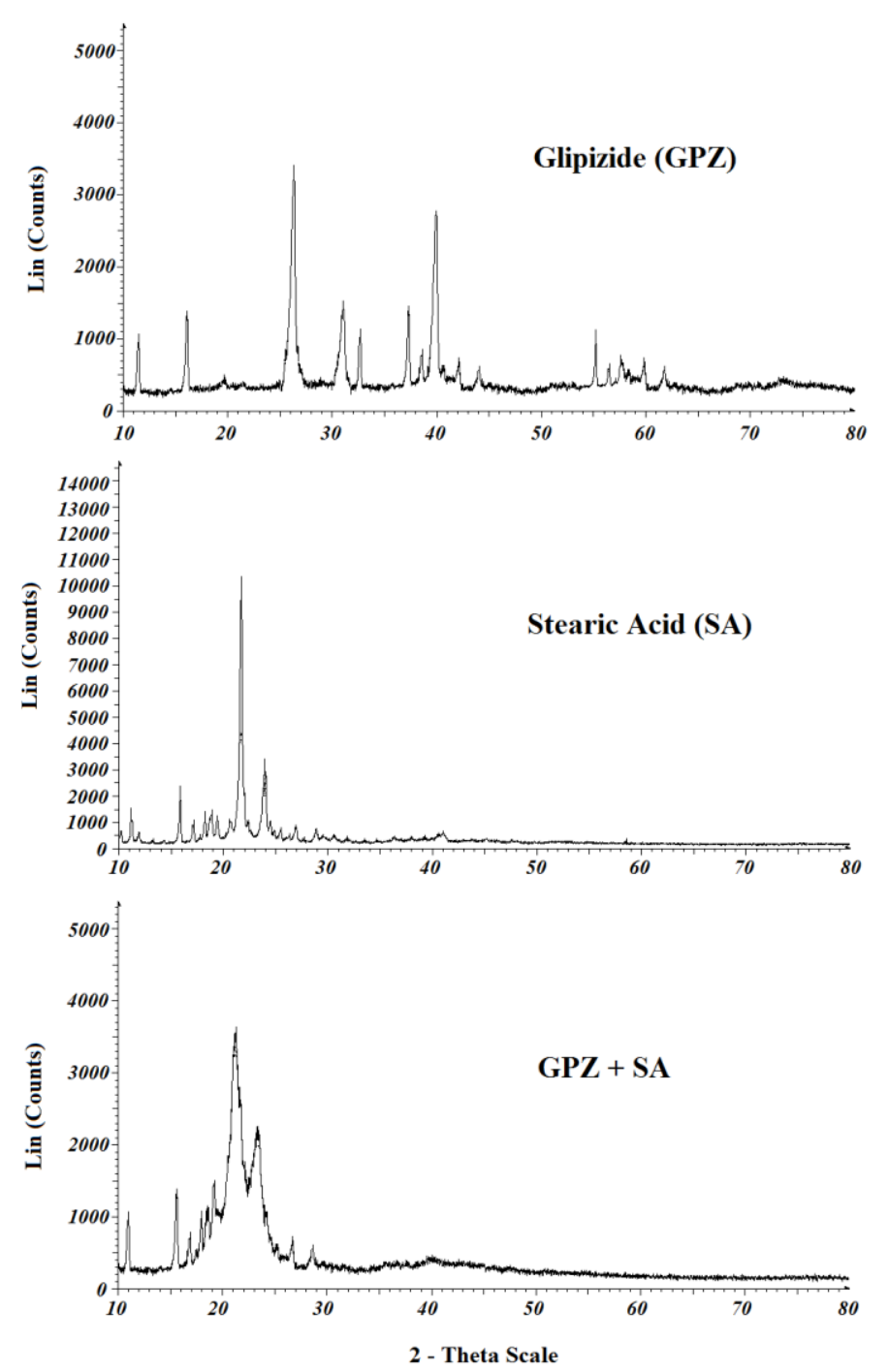

Figure 4 XRPD pattern of glipizide, stearic acid and corresponding physical binary mixtures $(\mathrm{GPZ}+\mathrm{SA})$ present in LM5

swelling ratio) but no swelling was observed with stearic acid as the calculated value for swelling ratio was found to be negative $(-0.17 \pm 0.06)$, indicating no swelling in the formulations after drug release.

Comparative study among F5 and glytop SR It can be observed (Fig 2B) that the drug release at $1^{\text {st }}$ hour was higher from
F5 than Glytop SR $^{\circledR}$ that will act as initial loading dose. On comparison of $\mathrm{T}_{50 \%}$ a highly significant difference $(\mathrm{P}<0.05)$ of $2.7 \mathrm{~h}$ was observed with formulation F5 (3 h) to that of Glytop SR ${ }^{\circledR}(5.7 \mathrm{~h})$. The similarity factor and dissimilarity factor for formulation F5, with reference to marketed preparation was $21.65 \%$ and $26.34 \%$ respectively. The drug release behavior can be justified on the basis 

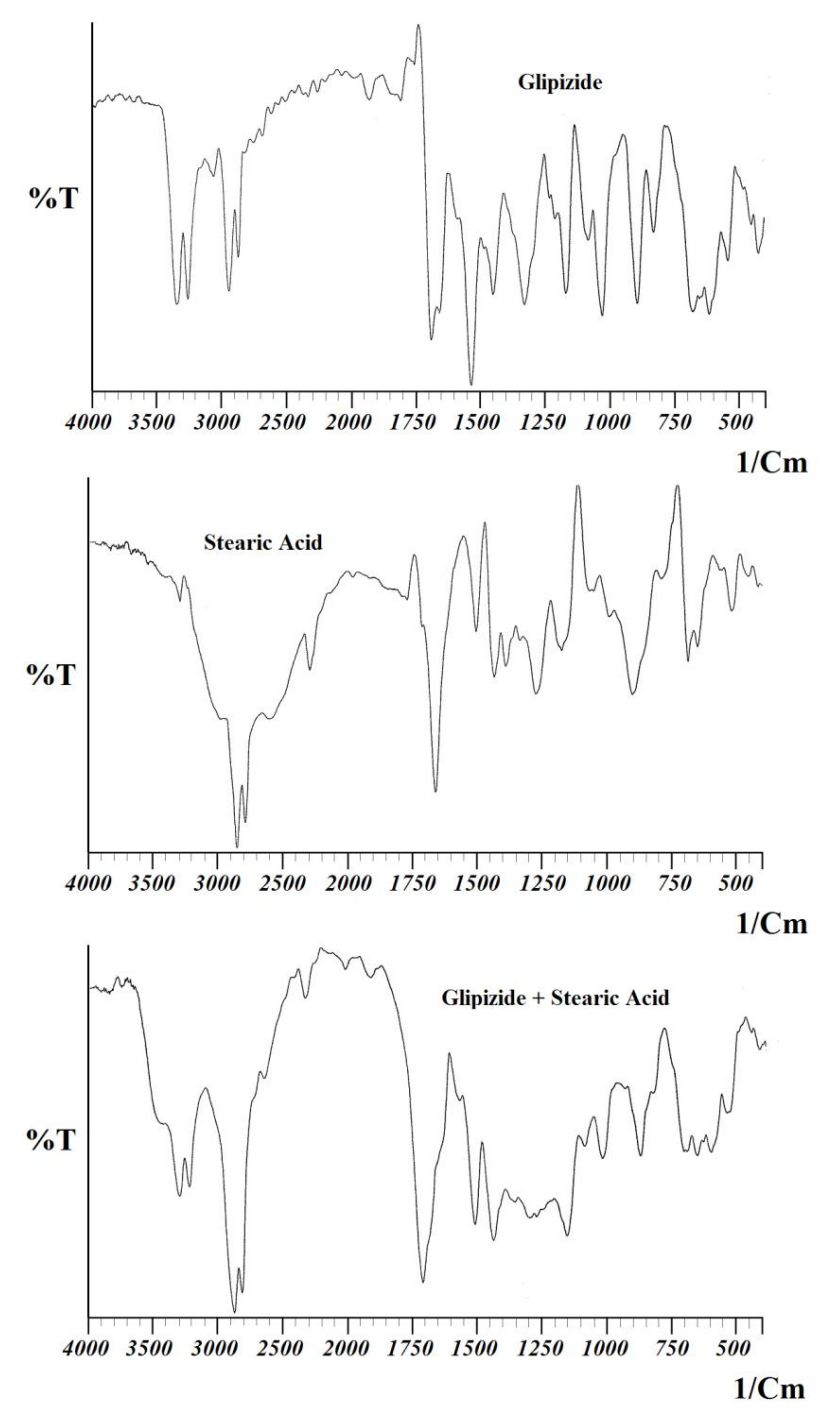

Figure 5 DRIFT spectra of glipizide, stearic acid and corresponding physical binary mixtures (Glipizide + Stearic Acid) present in LM5

of SEM photomicrographs captured before and after dissolution of the tablets (Fig. 6).

\section{Morphology of tablet surface}

The photomicrographs of formulation F5, before and after dissolution are shown in Figure 6, respectively. Formulation F5 retained its shape without disintegration throughout the dissolution process. Before the release test, the surface of the intact tablet (F5) appeared to be smooth (Fig. 6a). At the end of release test the tablet retained its shape but surface erosion coupled with cracks and fissures (Fig. 6b) were observed.

\section{Accelerated stability studies}

Accelerated stability studies were carried out by storing the formulation F5 at $40{ }^{\circ} \mathrm{C} / 75 \% \quad \mathrm{RH}$ for 6 months (climatic zone III conditions for accelerated stability testing) to assess their long term stability. At different time intervals of $0,1,2,3$ and 6 months, studies were conducted on formulation F5 to assess its stability 

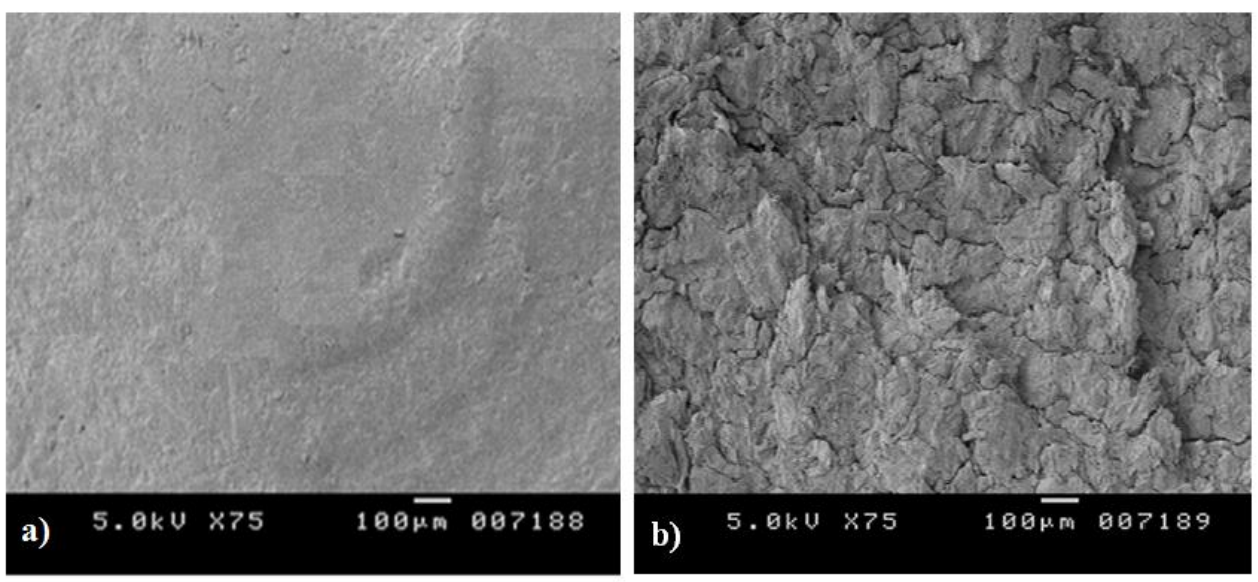

Figure 6 Scanning Electron Photomicrographs of a) Surface of F5 before dissolution; b) Surface of F5 after dissolution

with respect to their physical appearance, hardness, friability, drug content and in vitro drug release behavior. The optimized formulation after storing at $40{ }^{\circ} \mathrm{C} / 75 \% \mathrm{RH}$ for 6 months showed (Table 6), no significant change in physical appearance, hardness, friability and drug content. The above parameters determined for the evaluation of effect of different temperature and humidity conditions on the optimized formulations mainly by obtaining drug content, hardness and drug release from formulations. From accelerated stability studies it was found that the values for different parameters did not significantly $(\mathrm{P}$ $>0.05$ ) differ from each other. DRIFT analysis of prepared glipizide SR tablets was carried out in order to assess the instability of glipizide and lipids excipients which may be occurred due to the presence of other formulation ingredients i.e. aerosil, talc and magnesium stearate within the tablet or on long term storage of tablets. The DRIFT spectrum of glipizide tablet containing stearic acid showed the presence of characteristic peaks for glipizide at $3325.05 \mathrm{~cm}^{-1}$ and $1527.52 \mathrm{~cm}^{-1}$ for $\mathrm{N}-\mathrm{H}$ stretching and bending vibrations, respectively (Fig. 7). The stretching peaks appeared at $1699.17 \mathrm{~cm}^{-1}$ and $1650.95 \mathrm{~cm}^{-1}$ for $\mathrm{C}=\mathrm{O}$ of $-\mathrm{NHCONH}$ - and $-\mathrm{CONH}$ group, respectively. Two other stretching peaks were observed at $1161.07 \mathrm{~cm}^{-1}$ and $1039.56 \mathrm{~cm}^{-1}$ for $\mathrm{SO}_{2}$ and $\mathrm{C}-\mathrm{O}$ groups, respectively, while a $\mathrm{C}-\mathrm{H}$ bending vibration was observed at $896.84 \mathrm{~cm}^{-1}$ for disubstituted benzene (22), proved the existence of glipizide in prepared tablet with no instability (21). The spectra also showed the appearance of strong peaks for stearic acid at $3325.05 \mathrm{~cm}^{-1}$ and $1699.17 \mathrm{~cm}^{-1}$ for $\mathrm{O}-\mathrm{H}$ and $\mathrm{C}=\mathrm{O}$ stretching vibrations of $\mathrm{COOH}$. The $\mathrm{C}-\mathrm{H}$ stretching peaks were observed at $2939.31 \mathrm{~cm}^{-1}$ and $2861.08 \mathrm{~cm}^{-1}$ for $-\mathrm{CH}_{3}$ and $-\mathrm{CH}_{2}$ groups.

\section{Discussion}

As the objective of the study was to develop micromtarices based sustained release tablets of glipizide, therefore selection of the 
Table 5 Comparative data for drug release kinetics of optimized formulation (F5) and marketed formulation (Glytop SR ${ }^{\circledR}$ )

\begin{tabular}{|c|c|c|c|c|c|c|c|c|}
\hline $\begin{array}{c}\text { Formulation } \\
\text { Code }\end{array}$ & $\begin{array}{c}\text { Zero } \\
\text { order } \\
\left(\mathbf{r}^{2}\right)\end{array}$ & $\begin{array}{c}\text { First } \\
\text { order } \\
\left(\mathbf{r}^{2}\right)\end{array}$ & $\begin{array}{c}\text { Higuchi } \\
\left(\mathbf{r}^{2}\right)\end{array}$ & $\begin{array}{c}\text { Peppas } \\
\left(\mathbf{r}^{2}\right)\end{array}$ & $\begin{array}{c}\text { Hixson } \\
\text { Crowell } \\
\left(\mathbf{r}^{2}\right)\end{array}$ & $\begin{array}{c}\text { Constant } \\
\text { (k) }\end{array}$ & $\begin{array}{c}\text { Diffusion } \\
\text { exponent } \\
\text { (n) }\end{array}$ & $\begin{array}{c}\text { Order } \\
\text { of } \\
\text { release }\end{array}$ \\
\hline F5 & 0.9067 & 0.7907 & 0.9876 & 0.9723 & 0.8371 & 3.239 & 0.6776 & $\begin{array}{l}\text { Non- } \\
\text { Fickian }\end{array}$ \\
\hline Glytop SR ${ }^{\circledR}$ & 0.9794 & 0.9419 & 0.9637 & 0.9622 & 0.9626 & 2.838 & 0.6770 & $\begin{array}{l}\text { Non- } \\
\text { Fickian }\end{array}$ \\
\hline
\end{tabular}

Table 6 Stability data of optimized formulation F5, at different time interval for 6 months

\begin{tabular}{cccccc}
\hline Evaluation parameters & \multicolumn{5}{c}{ Time interval (months) } \\
\cline { 2 - 6 } & $\mathbf{0}$ & $\mathbf{1}$ & $\mathbf{2}$ & $\mathbf{3}$ & $\mathbf{6}$ \\
\hline Physical appearance & No change & No change & No change & No change & No change \\
Friability & Pass & Pass & Pass & Pass & Pass \\
Hardness (kg/cm $\left.{ }^{2}\right)$ & $5.66 \pm 0.47$ & $5.63 \pm 0.21$ & $5.56 \pm 0.54$ & $5.34 \pm 0.65$ & $5.28 \pm 0.32$ \\
Drug content & $99.54 \pm 0.96$ & $99.37 \pm 1.32$ & $98.99 \pm 0.03$ & $98.83 \pm 1.12$ & $98.32 \pm 0.98$ \\
\%CDR & $95.70 \pm 0.78$ & $95.72 \pm 0.65$ & $94.98 \pm 0.26$ & $94.86 \pm 0.88$ & $94.75 \pm 0.53$
\end{tabular}

suitable lipid is a primary need of the research in order to develop a successful dosage form. To initiate the research, compatibility of the binary mixtures of drug and excipients selected for the development of glipizide SR tablets was carried out and were found compatible and no physical interaction (caking, colour change, liquefaction and odor or gas formation) was observed. As shown in DSC thermograms a slight shift of the endotherm exhibited by glipizide may be due to the either of the two reasons; (i) reduction in melting point in the presence of low melting point substance (24), or (ii) conversion of crystalline glipizide to its amorphous form due the softening/dissolution of the drug in the melted matrix of compritol during simultaneous heating of both the component (25). The reduction in the intensity and the broadening exhibited by the endotherm of compritol 888 ATO in combination as compared to the thermogram exhibited by pure compritol indicate change in physical properties of the lipid in combination 
with the drug (Fig. 1A). This reduction in the melting range of glipizide may be due to the presence of amorphous stearic acid that resulted in less crystalline blend (26).

The DSC thermograms (Fig. 1B) showed no change in the melting endotherm of the stearic acid and the reduction observed in the intensity and $\Delta \mathrm{H}$ is due to change in heat of recrystallization in presence of any other crystalline substance (27). The change in base line may be due to the change in sample weight (due to volatilization) (28), or due to change in specific heat of the sample that occurs because of melting or crystallization of the lipid when lipid melt get converted to solid form (29). Thus DSC study revealed no significant shifting of peaks or appearance of new peaks confirming compatibility between glipizide and proposed lipids. Hence formulations can be safely designed using compritol 888 ATO and stearic acid as lipid excipients for development of controlled release tablet of glipizide. After confirming the compatibility among drug and excipients, drug-lipid micromatrices have been developed and subjected for further studies.

Insignificant difference between the values of drug content exhibited by the formulations reflecting uniform distribution of drug throughout the lipid micromatrices. Micomeritic evaluation showed that particle size has great influence on flow and packing behaviour of pharmaceutical granules (micromatrices) that can alter the volume to be filled in die when subjected for compression to tablets. Hence, in order to avoid potential manufacturing problems particle size determination is imperative. Even though the preparation steps were similar the difference in the particle size can be attributed to on-storage physical behavior of lipid micromatrices. The lower enthalpy values of stearic acid based matrices promoted phase transition in physical state that led to aggregation of particles thereby increasing the size. The negative values of IQCS thus obtained indicate large number of fine the particles present within the bulk and the IQCS values close to zero reflect almost symmetrical distribution (30). The low value(s) of standard deviation indicate that the particles are uniformly sized.

Grossly, the micromatrices were free flowing and were analyzed for their packing characteristics by bulk and tapped density determinations. The bulk density of powder is always less than the tapped density of its component particles because the powder contains inter-particle pores or voids. This implies that a powder can only possess a single true density, but it can have many different bulk densities, depending on the way in which the particles are packed (31). This property, in particularly important from industrial viewpoint where large bulk materials are handled and bulk density can affect the packaging and tablet manufacturing steps. Narrow range of bulk density and tapped density for all micromatrices 
indicating that the micromatrices will not present the manufacturing problems related to mixing of excipients to form a productive blend, transportation, flow throw the hopper during tablet compression and filling of die cavity.

Hausner's ratio is another means of defining the flow property. The favorable results represents that the developed micromatrices have good flow property. Another important property related to tablet blends is the compressibility index which is a direct measure of the potential powder arch or bridge strength and stability (17). The obtained values of Carr's index revealed high degree of compressibility (Table 3) that enable to produce physically and mechanically strong tablets required in case of sustained release tablet dosage forms.

The performance of SR tablet formulations is highly altered by human physiological and anatomical factors. Thus a sustained release dosage forms must attain sufficient strength to prevent the burst effect caused by gastrointestinal motility that may disturb the designed dosage form (9). A hardness of more than $4 \mathrm{~kg} / \mathrm{cm}$ reflects the potential of tablets to withstand the handling stress. The friability value less than $1 \%$, indicating that the formulations were mechanically stable. The amount of drug incorporated within the system is equivalent to the dose that is required to produce the optimum therapeutic effect. Any variation in the dose size leads to inefficiency or toxic therapy. Weight variation test of solid dosage form is a check point by which one can reduce the possibilities of above mentioned problems. Furthermore, a slight difference in the drug content indicates uniform mixing of drug with lipid excipients and other formulation excipients before compression of tablets.

In vitro drug release apparently showed the sustainment was better with compitrol based formulations but the extent of drug release is a primary consideration for an efficacious dosage form. Poor drug release from compritol matrices was due to coating of drug particles by the lipophilic drug release retardant material (compritol 888 ATO) that hardly allows the dissolution medium to enter into the matrix system (32). Thus compitrol based formulations can be rejected.

In stearic acid based formulations the minimum concentration of stearic acid was $15 \%$ by wt (claimed to be effective sustained release agent when used in more than $15 \%$; (33)) for F4 and rest of the formulations contained higher amount of stearic acid. Amongst F4 and $\mathrm{F}$, formulation $\mathrm{F} 4$ released the entire drug (99.64 $\pm 0.78 \%)$ within $11 \mathrm{~h}$. Hence F5 was selected as the best formulation with the \%CDR of $95.70 \pm$ $0.78 \%$. It was found that the difference in extent of drug release was dependent on stearic acid concentration in the delivery system.

Stearic acid is highly lipophilic in nature but the presence of hydroxyl groups imparts hydrophilic characteristics (9). This property of stearic acid gives it the 
tendency of being hydrated in dissolution medium and consequently stearic acid shows erodibility that may be the prominent mechanism of drug release through the micromatrices (34). SEM, XRPD and DRIFT was carried out to elucidate the possible mechanisms of drug release through F5, the micromatrices (LM5) that were used in the formulation of F5 was also studied extensively. SEM micrographs showed some longitudinal drug particles found adhered on the surface of micromatrices that being hydrophilic possibly contributed to initial rapid release that was further sustained because of the drug embedded within the lipid matrices. Moreover the uniform distribution of drug particles on/within the lipid micromatrices (Figure 3d) justifies the homogeneity of the blend that was responsible for uniform sustainment of drug release.

The X-ray powder diffraction diffractogram of glipizide showed crystallographic characteristics of pure glipizide reflecting the crystalline form of glipizide. The X-ray diffraction pattern of stearic acid reflecting the existence of higher crystalline state at near $22^{\circ}$ followed by amorphous state of the latter, confirming the presence of crystallinity in the pure form of stearic acid (Fig. 4). Micromatrices (GPZ + SA) showed the intense unchanged peaks of stearic acid, while there is no evidence of intense signals exhibited by glipizide, indicating that the drug has lost its crystallinity and exist in a complete amorphous form within the drug lipid micromatrix (LM5). The observed loss in crystallinity index of glipizide was resulted by the lipid coating of the drug particles as in lipid micromatrices the drug particles got embedded within the lipid bulk as proved by the SEM studies. The sustainment of the drug release as shown in in-vitro release studies strongly supports that the crystallinity was decreased due to lipid coating over drug particles rather than amorphization of drug that may cause solubility enhancement which in turn increases the drug release rate (29).

DRIFT analysis was conducted to assess any possible chemical change/interaction in LM5 comparing with the spectra of pure glipizide and stearic acid that may be the major parameter responsible for drug release behavior. Results showed that all the characteristic peaks appeared in the spectra with minute shift in wave numbers confirming its purity and it was used as reference for other spectral interpretations. Stearic acid is a fatty acid containing saturated carbon chain along with carboxyl group and its identification mainly depends upon the methyl, methylene, carboxyl and hydroxyl groups. The carboxyl group imparts lipophilicity and hydroxyl group confers hydrophilic character. Furthermore, the presence of all the characteristic peaks with shift in wave numbers in acceptable range, in the spectra of micromatrices (LM5) revealed that groups responsible for antidiabetic action in glipizide did not 
undergo chemical changes during the development of micromatrices by hot fusion method. It also suggests that stearic acid used as a coating agent modifies the surface property of the glipizide and forms continuous matrix that hinders the interaction of drug with dissolution media and sustained the drug release from $\mathrm{F} 5$ for $12 \mathrm{~h}$.

The drug release profiles of formulation F5 and marketed formulation (Glytop $\left.\mathrm{SR}^{\circledR}\right)$ were subjected to mathematical modeling in order to determine the kinetics and order of drug release. The modeling of in vitro drug release data suggested that the formulation F5 exhibited non-Fickian release pattern that indicates combined mechanism of drug release(Table 5). Furthermore, the values obtained by mathematical modeling, it has been proved that F5 was superior on the basis of model dependent parameters among all the formulations containing stearic acid. The objective of the study was to develop an alternative sustained release formulation of glipizide over the commercially available equivalent dosage form. In order to justify the performance efficacy of F5 a comparative study on drug release behavior was conducted for F5 and Glytop $\mathrm{SR}^{\circledR}$. The comparative profile of formulation F5 and Glytop SR ${ }^{\circledR}$ suggests that F5 exercises better control on drug release that provides an edge over Glytop $\mathrm{SR}^{\circledR}$. The similarity factor was greater than $15 \%$, while dissimilarity factor was less than $50 \%$ indicating difference in drug release profiles of F5 and marketed preparation. The photomicrographs of formulation F5, before and after dissolution are shown in Figure 6, respectively. At the end of release observed surface erosion coupled with cracks and fissures can be explained by the tendency of stearic acid to get eroded due to the hydrophilic groups $(-\mathrm{OH})$ leading to cracks that facilitated drug release.

Waxy materials are prone to oxidation in the presence of oxygen. The rate of oxidation of such compounds increases with increase in the degree of unsaturation and temperature (35). Thus, the main objective of stability study was to ensure the stability of lipids with drug within the formulation on long term storage. The optimized formulation obtained on the basis of in vitro drug release studies, the formulation F5 was found to fulfill the objective of sustaining the drug release for 12 hours. The optimized formulation after storing showed no significant change in physical appearance, hardness, friability and drug content. On analysis DRIFT spectra appearance of the characteristic peaks reveals the stability of glipizide and stearic acid within the tablet (Fig. 7). The other peaks observed in the spectra are due to the presence of aerosil, talc, magnesium stearate and microcrystalline cellulose in the tablet. The existence of appropriate characteristic peaks in the spectra with the acceptable shift in the range of wave numbers confirmed that there was no instability or chemical change occurs in the drug as well as in stearic acid. This proves the suitability of lipid (stearic 

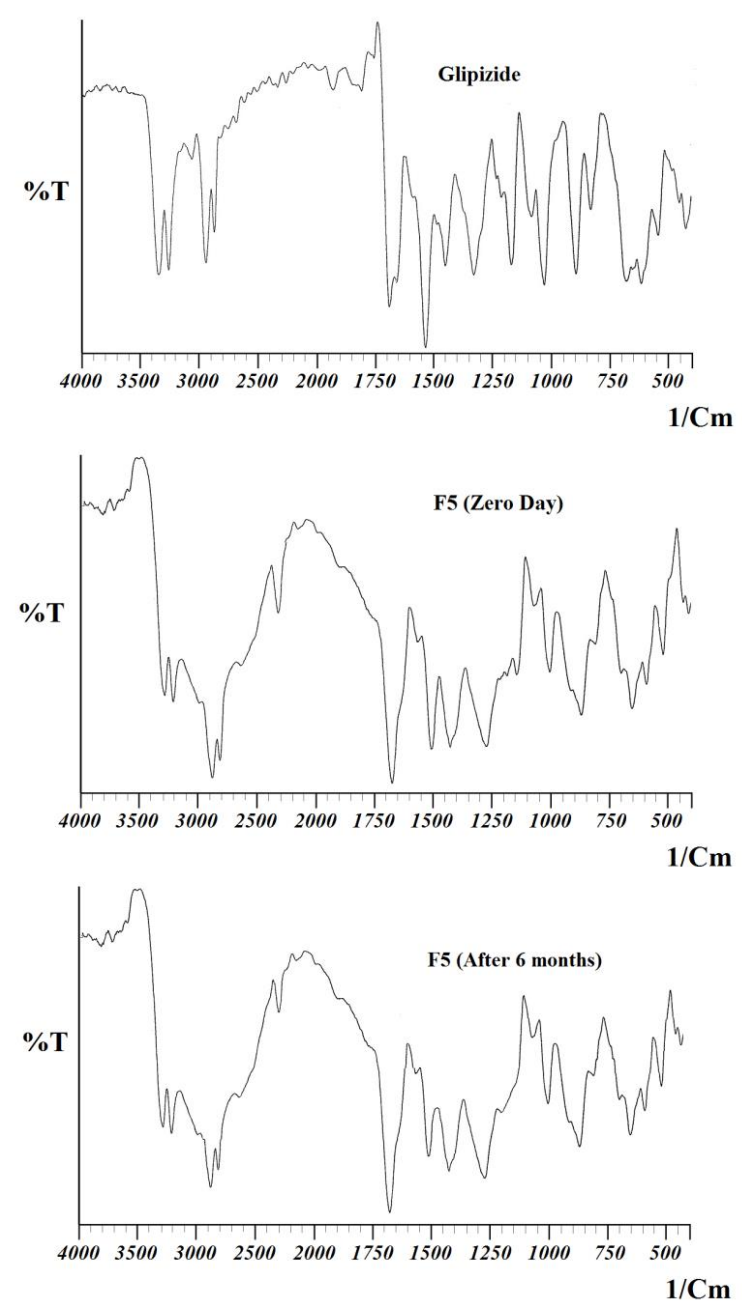

Figure 7 DRIFT spectra of glipizide, F5 (Zero Days) and F5 (After Six Months) for stability studies

acid) as an effective release retardant which does not exhibit any significant change in their property with time. As observed from the results of stability formulation F5, was found satisfactory on the basis of its performance behaviour. So, stearic acid has been found suitable for the development of sustained release tablet dosage form in the optimum concentration.

\section{Conclusion}

From the study it was concluded that the lipid excipients that is compritol 888 ATO and stearic acid are effective release retardants. The release of active constituent can be easily modified or sustained by using appropriate amount of stearic acid. The results showed that drug release can be significantly sustained by the incorporation of 
effective release retardant like stearic acid. As the results suggest that stearic acid was found suitable for retarding the drug release, however a $\mathrm{CR}$ can be developed by mixed lipid formulations.

\section{References}

1. Uner M, Gonullu U, Yener G, Altinkurt T. A new approach for preparing a controlled release ketoprofen tablets by using beeswax. II Farmaco 2005;60:27-31.

2. Weiner AL. Lipids as Excipients in Pharmaceutical Dosage Forms, In: Encyclopedia of Pharmaceutical Technology. 2nd Edition. Marcel Dekker Inc., New York, 2001:1659-73.

3. Dakkuri A, Schroeder HG, Deluca PP. Sustained release from inert matrixes II: effect of surfactants on Tripelennamine Hydrochloride release. J Pharm Sci 1978; 67: 354-7.

4. Hassan EE, Eshra AG, Nada AH. Formulation of prolonged release lipid micropellets by emulsion congealing: Optimization of ketoprofen entrapment and release. Int J Pharm 1995;121:149-55.

5. Wu LNY, Genge BR, Kang MW, Arsenault AL, Wuthier RE. Changes in phospholipid extractability and composition accompany mineralization of chicken growth plate cartilage matrix vesicles. J Biol Chem 2002; 277: 5126-33.

6. Lee BJ, Choe JS, Kim CK. Preparation and characterization of melatonin-loaded stearyl alcohol microspheres. J Microencap 1998; 15:775-87.

7. Sudha BS, Sridhar BK, Srinatha A. Modulation of Tramadol Release from a Hydrophobic Matrix: Implications of Formulations and Processing Variables. AAPS Pharm Sci Tech 2010; 11: 433-40.

8. Hamdani J, Moes AJ, Amighi K. Physical and thermal characterization of Precirol ${ }^{\circledR}$ and Compritol ${ }^{\circledR}$ as lipophilic glycerides used for the preparation of controlledrelease matrix pellets. Int J Pharm 2003;260:47-57.

9. Ozyazici M, Gokce EH, Ertan G. Release and diffusional modeling of metronidazole lipid matrices. Eur $\mathrm{J}$ Pharm Biopharm 2006; 63: 331-9.

10. Li FQ, Hu JH, Deng JX, Su H, Xu S, Liu JY. In vitro controlled release of sodium ferulate from Compritol 888 ATO-based

\section{Conflict of interest}

The authors report no conflict of interest. The authors alone are responsible for the content and writing of the paper.

matrix tablets. Int J Pharm 2006;324:152-7.

11. Barthelemy P, Laforet JP, Farah N, Joachim J. Compritol 888 ATO: an innovative hot-melt coating agent for prolonged-release drug formulations. Eur $\mathbf{J}$ Pharm Biopharm 1999;47:87-90.

12. Cao QR, Kim TW, Lee BJ. Photoimages and the release characteristics of lipophilic matrix tablets containing highly watersoluble potassium citrate with high drug loadings. Int J Pharm 2007;339:19-24.

13. Hsieh SH, Lin JD, Cheng HY, Ho C, Liou MJ. Sustained-release versus immediaterelease glipizide for treatment of type 2 diabetes mellitus in chinese patients: A randomized, double-blind, double-dummy, parallel-group, 12-week clinical study. Clin Ther 2006;28:1318-26.

14. Carstensen JT, Rhodes CT. Drug stability principles and practices, $4^{\text {th }}$ Edition. Marcel Dekker Inc. New York, 2000; 254-6.

15. Sinko JP. Martin's Physical pharmacy and pharmaceutical sciences, $5^{\text {th }}$ Edition. Lippincott Williams \& Wilkins, New Delhi, India, 2008;423-52.

16. British Pharmacopoeia. The stationary office under license from the controller of Her Majesty's stationary office for the department of health on behalf of Health Minister, Controller of Her Majesty's stationary office \& Queen's printer, London, United Kingdom 2004; Appendix -358 .

17. Aulton ME. The science of dosage form design, $3^{\text {rd }}$ Edition. Churchil Livingstone, Elsevier, New York 2008:139-97.

18. Indian Pharmacopoeia. Government of India, Ministry of Health and Family Welfare, Controller of Publication, New Delhi, India, Vol - I \& II: 2007.

19. Rowe CR, Sheskey PJ, Owen SC. Handbook of pharmaceutical excipients. Pharmaceutical press: London 2006; 461-5.

20. The United States Pharmacopeia 27/ National Formulary 22, United States 
Pharmacopoeial Convention, Rockville, M. D. 2006;3306-7.

21. Moffat AC, Osselton MD, Widdop B. Clarke's Analysis of Drugs and Poisons, London: Pharmaceutical Press, Great Britain. 2005;116-8.

22. Pavia DL, Lampman GM, Kriz GS. Introduction to Spectroscopy, 3rd Edition, Cengage, India. 2001;142-3.

23. Silverstein RM, Webster FX. Spectrometric identification of organic compounds, John Wiley and Sons Inc., New York. 2003;71-111.

24. Janaik C, Lassa PG, Lassa HN. The vinyl homo-polymerization of norbornene. Macromol Rapid Commun 2001;22:47993.

25. Rahman PKSM, Pasirayi G, Auger V, Ali Z. Production of rhamnolipid biosurfactants by Pseudomonas aeruginosa DS10-129 in a microfluidic bioreactor. Biotech Appl Biochem 2010;55:45-52.

26. Teixeira SR, Romero M, Rincon JM. Crystallization of $\mathrm{SiO} 2-\mathrm{CaO}-\mathrm{Na} 2 \mathrm{O}$ glass using sugarcane bagasse ash as Silica Source. J Am Ceram Soc 2010b; 93: 450455.

27. Desai SR, Shaikh MM, Dharwadkar SR. Preformulation compatibility studies of etamsylate and fluconazole drugs with lacose by DSC. J Therm Anal Cal 2003;71:651-8.

28. Puglisi G, Fresta M, Giammona G, Ventura CA. Influence of the preparation conditions on poly (ethylcyanoacrylate) nanocapsule formation. Int $\mathbf{J}$ Pharm 1995;125:283-7.

29. Kalepu S, Manthina M, Padavala V. Oral lipid-based drug delivery systems - an overview. Acta Pharmaceutica Sinica B 2013;3:361-72.
30. Dabas S, Shakya P, Sharma V, Pathak K. Effect of milling on correlation between interquartile coefficient of skewness and coefficient of kurtosis in pharmaceutical powders - II. Ind J Pharm Edu Res 2009;43:272-9.

31. Subramanyam CVS. Textbook of physical pharmaceutics, $2^{\text {nd }}$ Edition. Vallabh Prakashan, New Delhi. 2009;225-38.

32. Barakat NS, Elbagory IM, Almurshedi AS. Controlled-Release Carbamazepine Granules and Tablets Comprising Lipophilic and Hydrophilic Matrix Components. AAPS Pharm Sci Tech 2008;9:1054-62.

33. Bhagwat DA, Kawtikwar PS, Sakarkar DM. Sustained Release Matrices of Verapamil $\mathrm{HCl}$ Using Glyceryl Monosterate and Stearic Acid. Research J Pharm Tech 2008;4:46-55.

34. Hayashi T, Kanbe H, Okada M, Suzuki M, Ikeda Y, Onuki Y, Kaneko T, Sonobe T. Formulation Study and Drug Release Mechanism of a New Theophylline Sustained- Release Preparation. Int J Pharm Sci 2005;304:91-101.

35. Aguilar AR, Moreno PS, Reyes ABJ, Rodriguez AM, Boulaiz H, Corrales JAM, Garcia JMP, Vinuesa JLO. Colloidal stability and "in vitro" antitumor targeting ability of lipid nanocapsules coated by folate-chitosan conjugates. J Bioact Compat Poly: Biomed Appl 2012;27:388404. 